\title{
Changes in Work Ability after Weight-Loss Surgery: Results of a Longitudinal Study of Persons with Morbid Obesity before and after Bariatric Surgery
}

\author{
Hinrich Köhler ${ }^{a}$ Valentin Markov ${ }^{b}$ Anna Watschke ${ }^{c}$ Kerstin Gruner-Labitzke $^{a}$ \\ Clara Böker ${ }^{d}$ Christoph Kröger ${ }^{b}$

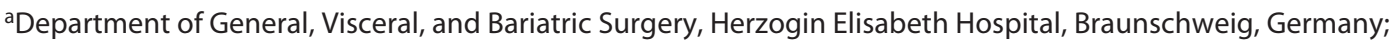 \\ ${ }^{b}$ Department of Psychology, University of Hildesheim, Hildesheim, Germany; ' Department of Psychology, University

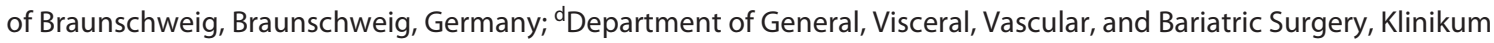 \\ Nordstadt, Hannover, Germany
}

\section{Keywords}

Obesity · Body mass index · Work ability · Bariatric surgery

\begin{abstract}
Introduction: Bariatric surgery is a life-changing treatment, but knowledge of its influence on changes in work ability is still limited. We hypothesized that self-reported work ability improves in response to surgery-induced weight loss and sociodemographical variables (e.g., age, sex, and marital status), and that psychosocial characteristics (e.g., depressive symptoms and dysfunctional eating) may have predictive value as to patients' work ability. Methods: A total of 200 participants scheduled for bariatric surgery were recruited between September 2015 and June 2018. They completed several self-report measures at the preoperative examination (t1) and at 6- (t2) and 12 months (t3) after bariatric surgery. A repeated-measures analysis of variance was calculated to detect any changes in the work ability and body mass index (BMI) among the 3 time points. Further, a hierarchical multiple regression analysis was used to determine whether any demographical and psychosocial characteristics at (t1) would predict work ability at (t3). Results: Participants $(82 \%$ of whom were women) were middle-aged and showed a BMI of
\end{abstract}

karger@karger.com www.karger.com/ofa

Karger $\stackrel{\text { ' }}{5}$

GOPEN ACCESS
(C) 2021 The Author(s)

Published by S. Karger AG, Basel

This is an Open Access article licensed under the Creative Commons Attribution-NonCommercial-4.0 International License (CC BY-NC) (http://www.karger.com/Services/OpenAccessLicense), applicable to the online version of the article only. Usage and distribution for commercial purposes requires written permission. nearly 46 at the preoperative medical examination. Excess weight loss at (t2) and at (t3) was 49 and $66 \%$, respectively. Work ability increased toward a moderate level after weightloss surgery. Work ability and dysfunctional eating at ( $\mathrm{t} 1$ ) showed significant predictive value with respect to work ability at (t3). Discussion: The results suggest that weightloss surgery has a positive impact on work ability, and indicate a predictive value for the extent of weight loss and dysfunctional eating behavior. Against our hypothesis and in contrast to former research, a predictive value for depressive symptoms and age was not revealed. Further research must show how interventions can support and maintain improvements in work ability after bariatric surgery, in order to reduce sick leave and unemployment in patients with preoperative morbid obesity.

(c) 2021 The Author(s)

Published by S. Karger AG, Basel

\section{Introduction}

While the prevalence of obesity is increasing worldwide, the complexity of the disease is still not completely understood. There is no doubt that obesity impairs quality of life, encompassing reduced physical and mental 
health, and therefore work ability [1-3]. These negative consequences of obesity-related diseases result in a high degree of psychological strain.

Health-related quality of life is significantly impaired in the obese population with respect to psychosocial functioning and mental health [4-6] and may improve after surgical intervention, with effects that can last for $>10$ years [7]. Following bariatric surgery, 1 group of researchers found that $20-51 \%$ of queried patients mentioned positive postoperative changes on functioning indices; only $3-10 \%$ mentioned a negative impact [6]. While weight-loss surgery undoubtedly leads to psychosocial changes in patients' everyday lives [8], knowledge of its influence on work ability remains limited. Being overweight above the normal range is progressively associated with lower work ability in relation to the physical demands of the job [9]. Using the bariatric analysis and reporting outcome system in the course of a long-term survey of 92 persons following gastric bypass surgery, Askari et al. [10] documented better ability to work.

Earlier studies outlined an association between overweight status and the inability to work due to illness [11]. According to Ewing et al. [12], American workers seeking bariatric surgery miss an average of 33 workdays in the preoperative year due to illness, compared with only 3 days lost to illness for typical American workers. Weightloss surgery aimed to reduce the risk of work impairment and premature early retirement [2]. Other research documented the impact of bariatric surgery on psychosocial outcome variables, and looked at their predictive value for work ability in morbidly obese subjects. Depression was identified as a strong independent predictor for work ability, while morbid obesity indicated a strong prediction for work impairment [13].

Depressive tendencies and quality of life were identified as significant psychosocial predictors for increased labor productivity and reduction of work related-impairment after bariatric surgery [14]. Only a few studies have investigated work ability as a primary outcome for persons seeking bariatric surgery, and these studies have only rarely reported any psychosocial predictors of work ability before and after bariatric surgery $[6,7,14,15]$. Thus, it is still unclear which psychosocial factors can influence or predict work ability after bariatric surgery.

The present study examines the influence of weightloss surgery on work ability. We had already showed that work ability was low in the obese population prior to surgery at a bariatric center in Germany [16]. Next, we aimed to report the further course of 200 patients who were morbidly obese prior to surgery; of these, we were able to get in touch with 127 of them at 6 months post-surgery, and 89 of them at 12 months post-surgery.

We hypothesized that work ability will improve after bariatric surgery due to the resulting significant weight loss, and that the amount of weight lost may have an influence on the degree of improvement. Further, this study investigated the influence of sociodemographic variables (age, sex, and marital status) and psychosocial factors (depressive symptoms, dysfunctional eating behavior, and life satisfaction) and their predictive value on changes in work ability. An earlier study revealed the predictive effects of age, life satisfaction, and depressive states on the work ability of morbidly obese persons [16]. These factors might have an influence on changes in work ability after weight-loss surgery, possibly in proportion to the amount of weight lost. To date, the impact of these factors on work ability after weight-loss surgery has not been assessed in studies with a longitudinal design.

\section{Methods}

The present study was approved by the Institutional Ethics Committee of the University of Braunschweig (M-2015-07) and conducted in accordance with the Helsinki Declaration.

\section{Study Design and Subjects}

The study was conducted at the Department of General, Abdominal, and Bariatric Surgery at Herzogin Elisabeth Hospital in Braunschweig, Germany, between September 2015 and June 2018, as part of a larger longitudinal investigation. The subjects were persons suffering from morbid obesity who visited the department seeking bariatric surgery, including sleeve gastrectomy or gastric bypass. Each patient received a detailed explanation of the surgical and study procedures. Participation was completely voluntary and without financial incentives. In all, 200 patients were included in the study, prior to which they were asked to sign a written informed consent form. Patients who met our inclusion criteria were between 18 and 65 years of age and had a preoperative body mass index (BMI) $\left(\mathrm{kg} / \mathrm{m}^{2}\right)$ above 35, indicating an obesity grade of 2 or 3. Exclusion criteria were insufficient German language skills, intellectual disability, developmental or learning disorders, a history of prior bariatric surgery, and current substance abuse. Participants were invited to report sociodemographic characteristics (e.g., age, sex, marital status, and BMI) and to complete several self-report measures that assess psychosocial factors at the preoperative medical examination (t1) and at $6(\mathrm{t} 2)$ and 12 months $(\mathrm{t} 3)$ after bariatric surgery.

\section{Measures}

We used standardized self-report measures to examine depressiveness, relationship satisfaction, work ability, life satisfaction, and dysfunctional eating behavior. Participants completed the $\mathrm{Pa}$ tient Health Questionnaire - Depression Scale (PHQ-9) [17], the short form of the Relationship Questionnaire (PFB-K) [18], the Work Ability Index (WAI) [19], the Life Satisfaction Question- 
Table 1. Sociodemographic characteristics

\begin{tabular}{|c|c|c|c|c|c|c|c|c|c|}
\hline \multirow[t]{2}{*}{ Time points } & \multicolumn{3}{|l|}{1} & \multicolumn{3}{|l|}{2} & \multicolumn{3}{|l|}{3} \\
\hline & $M(S D)$ & $n$ & $\%$ & $\mathrm{M}(\mathrm{SD})$ & $n$ & $\%$ & $\mathrm{M}(\mathrm{SD})$ & $N$ & $\%$ \\
\hline Women & & 162 & 82.2 & & 107 & 84.3 & & 72 & 80.9 \\
\hline Men & & 35 & 17.8 & & 20 & 15.8 & & 17 & 19.1 \\
\hline All & & 197 & 100 & & 127 & 64.5 & & 89 & 45.2 \\
\hline Age, years & $44.9(11.4)$ & 197 & 100 & $45.3(11.2)$ & 197 & 100 & $45.9(11.4)$ & 197 & 100 \\
\hline Marital status & & 197 & 100 & & 127 & 64.5 & & 89 & 45.2 \\
\hline Single & & 31 & 15.7 & & 18 & 14.2 & & 8 & 9.0 \\
\hline In relationship & & 32 & 16.2 & & 28 & 22.1 & & 18 & 20.2 \\
\hline Married & & 113 & 57.4 & & 70 & 55.1 & & 49 & 55.1 \\
\hline Divorced/widowed & & 21 & 10.6 & & 11 & 8.7 & & 14 & 15.7 \\
\hline Children & & 143 & 72.6 & & 90 & 70.9 & & 67 & 75.1 \\
\hline Years of education & & 192 & 97.5 & & 127 & 64.5 & & 89 & 45.2 \\
\hline 8 or less & & 7 & 3.5 & & 4 & 3.2 & & 2 & 2.3 \\
\hline 9 & & 72 & 36.5 & & 47 & 37.0 & & 38 & 42.7 \\
\hline 10 & & 79 & 40.1 & & 51 & 40.2 & & 31 & 34.8 \\
\hline 13 & & 24 & 12.2 & & 17 & 13.4 & & 10 & 11.2 \\
\hline 17 or more & & 10 & 5.1 & & 8 & 6.3 & & 8 & 9.0 \\
\hline Professional training & & 157 & 79.7 & & 103 & 81.1 & & 75 & 84.3 \\
\hline Current occupation & & 120 & 60.9 & & 72 & 56.7 & & 50 & 56.2 \\
\hline $\mathrm{BMI}, \mathrm{kg} / \mathrm{m}^{2}$ & $45.7(7.3)$ & 197 & 100 & $35.9(6.4)$ & 197 & 100 & $33.3(5.2)$ & 197 & 100 \\
\hline $\begin{array}{l}\text { Psychotherapeutic } \\
\text { treatment }\end{array}$ & & 192 & 97.5 & & 127 & 64.5 & & 89 & 45.2 \\
\hline Former & & 93 & 47.2 & & 53 & 41.7 & & 37 & 41.6 \\
\hline Current & & 31 & 15.7 & & 13 & 10.2 & & 8 & 9.0 \\
\hline
\end{tabular}

The sample sizes vary because of missing data. The $n$-values of age and BMI, and their percentile ranks are based on the best-fitted imputed dataset to $\mathrm{t} 1$. All other percentile ranks are based on the $n$-values of the respective measurement times. $\mathrm{M}$, mean; SD, standard deviation; BMI, body mass index; $n$, sample size; $\%$, percentile ranks.

naire Modules (FLZ $\left.{ }^{\mathrm{M}}\right)[20]$, and the short form for detecting Abnormal Eating Behavior (KFzE) [21]. Psychometric quality indices were described in a previous study [16]. Internal consistency values were moderate at the 3 time points of assessment (see Table 1).

\section{Data Analysis}

Data analyses were performed using the IBM Statistical Package for Social Sciences (IBM SPSS, version 26). Missing data for all values were analyzed using the Missing Value Analysis method implemented in SPSS. Little's MCAR-Test [22] showed that incomplete values were missing at random $\left(n=197, \chi^{2}(21,747)=\right.$ $15,963.406, p=1.00)$. For substitution of the missing data, a multiple imputation method was chosen [23]. In accordance with this method, 20 imputed datasets were calculated per the Markov chain Monte Carlo (MCMC) procedure to estimate the parameters of the missing values at the best-fitted probability distribution. Thus, the missing data were replaced with the best-fitted equal values, and the dataset was completed. A combined dataset of the 20 imputed datasets was compiled, and this became the basic dataset for all calculations.

A repeated-measures analysis of variance (ANOVA) was used as a statistical method to detect any significant differences in the WAI and BMI among the 3 time points of assessment. Post hoc $t$ tests were performed for comparison of differences between and within these time points. In addition, an analysis of covariance was applied to explore whether some sociodemographic characteristics might influence any differences in the WAI among the 3 time points.

The impact of the BMI reduction size on WAI at the last measurement time was performed. Reduction size was calculated by splitting the mean score into 2 groups of higher half and lower half of BMI reduction. Then, BMI reduction size was implemented as a between-subject variable in an ANOVA for WAI.

Weight loss at 6 and 12 months after bariatric surgery was expressed as a percentage of excess weight lost, as well as percentage of total body weight lost. Ideal body weight was calculated as the equivalent of a BMI of $25 \mathrm{~kg} / \mathrm{m}^{2}$, with excess BMI $>25 \mathrm{~kg} / \mathrm{m}^{2}$.

A hierarchical multiple regression analysis was calculated, to examine the predictive value of the demographic characteristics and psychosocial scorings recorded at the preoperative medical examination as they affect work ability at 12 months after surgery. In the first block, the demographic characteristics age, sex, and $\mathrm{BMI}$ at the first measurement time point were taken gradually into the model as controls. In the second block, the values of the psychosocial scorings at the first measurement time point were included in the stepwise multiple regression, to investigate a possible influence on the WAI scores at 12 months.
38

Obes Facts 2022;15:36-45

DOI: $10.1159 / 000519269$
Köhler/Markov/Watschke/GrunerLabitzke/Böker/Kröger 
Table 2. Descriptive data of the standardized self-report measures

\begin{tabular}{|c|c|c|c|c|c|c|c|}
\hline & \multicolumn{7}{|c|}{ Range of values } \\
\hline & time points & M & SD & $a$ & possible & available & skewness \\
\hline WAI & 1 & 26.31 & 8.91 & 0.82 & $7-49$ & $7-48$ & -0.22 \\
\hline PHQ-9 & & 8.56 & 5.05 & 0.84 & $0-27$ & $0-23$ & 0.58 \\
\hline KFzE & & 22.99 & 7.94 & 0.80 & $0-48$ & $4-43$ & -0.13 \\
\hline PFB-K & & 17.95 & 5.12 & 0.81 & $0-27$ & $4-27$ & -0.60 \\
\hline $\mathrm{FLZ}^{\mathrm{M}}$ & & 49.95 & 13.83 & 0.76 & $0-100$ & $21.51-93.58$ & 0.26 \\
\hline WAI & 2 & 34.74 & 7.49 & 0.75 & $7-49$ & $7-49$ & -0.97 \\
\hline PHQ-9 & & 4.36 & 3.30 & 0.73 & $0-27$ & 0-19 & 1.19 \\
\hline KFzE & & 10.61 & 5.73 & 0.71 & $0-48$ & $0-28$ & 0.54 \\
\hline PFB-K & & 19.67 & 4.17 & 0.69 & $0-27$ & $9-27$ & -0.36 \\
\hline $\mathrm{FLZ}{ }^{\mathrm{M}}$ & & 61.82 & 12.83 & 0.77 & $0-100$ & $29.06-96.60$ & 0.21 \\
\hline WAI & 3 & 33.77 & 6.32 & 0.66 & $7-49$ & $13-46$ & -0.54 \\
\hline PHQ-9 & & 5.96 & 3.52 & 0.66 & $0-27$ & $0-23$ & 0.80 \\
\hline KFzE & & 11.96 & 5.15 & 0.63 & $0-48$ & $0-29$ & 0.51 \\
\hline PFB-K & & 19.20 & 3.89 & 0.69 & $0-27$ & $5-27$ & -0.55 \\
\hline $\mathrm{FLZ}^{\mathrm{M}}$ & & 57.07 & 11.73 & 0.69 & $0-100$ & $22.64-96.60$ & 0.94 \\
\hline
\end{tabular}

WAI, Work Ability Index; PHQ-9, Patient Health Questionnaire - Depression Scale; KFzE*, Measure for Detecting Abnormal Eating Behavior; PFB-K*, Short form of the Relationship Satisfaction Questionnaire; FLZ ${ }^{\mathrm{M} *}$, Life Satisfaction Questionnaire Modules; M, mean; SD, standard deviation; $a$, Internal Consistency Coefficient Cronbach's $a .{ }^{*}$ German Abbreviation.

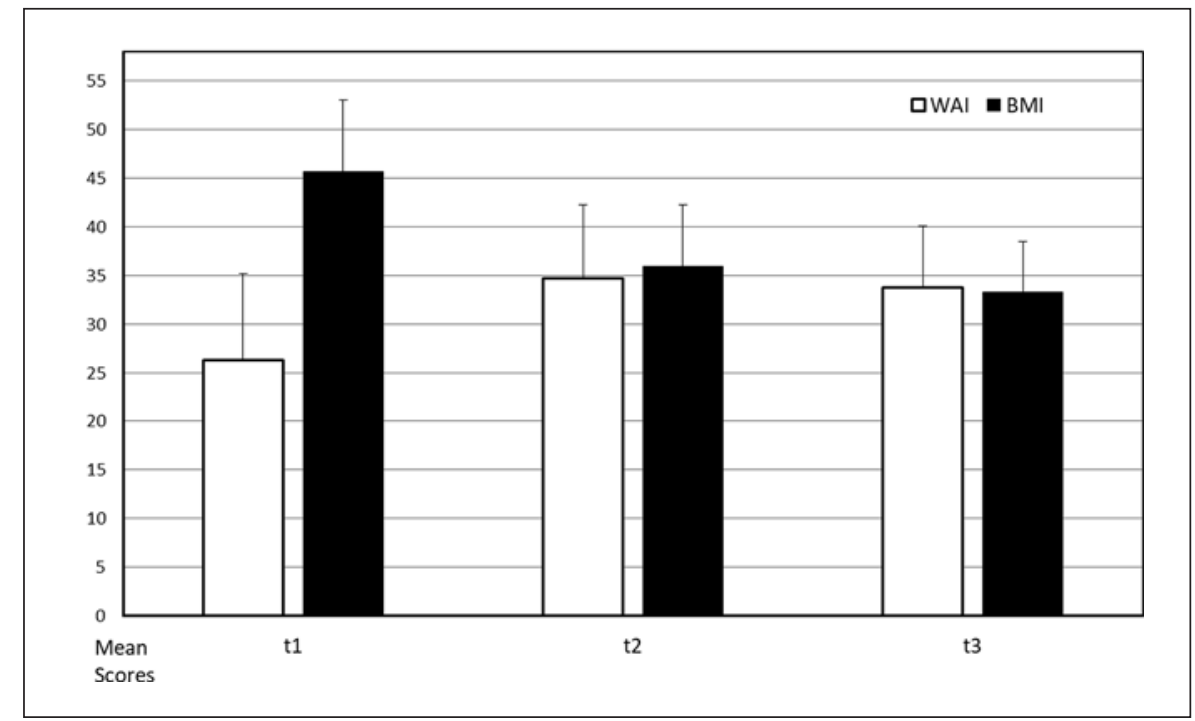

Fig. 1. Positive change of work ability and BMI over time. X-Axis, measurement times; Y-Axis, mean scores; error bars, SD; white bars, WAI mean scores; black bars, BMI mean scores. SD, standard deviation; WAI, Work Ability Index; BMI, body mass index.

\section{Results}

Three patients at (t1) were excluded because $>30 \%$ of the answers on their self-report measures were missing at the preoperative time point. The dropout rate among the remaining 197 patients at $(\mathrm{t} 1)$ was $35.53 \%(n=70)$ at 6 months and $54.82 \%(n=108)$ at the 12-months follow-up assessment. Sociodemographic characteristics are listed in
Table 2. Descriptive data of the standardized self-report measures are displayed in Table 1. Most of these data showed an almost exhaustive range of values at all measurement points, except for the FLZ ${ }^{\mathrm{M}}$, the PHQ-9, and the $\mathrm{KFzE}$ at the second and last measurement points. A slight positive skewness was observed by the values of the PHQ9 at the second and last measurement points and by the values of the FLZ ${ }^{\mathrm{M}}$ at the last measurement point, while a 
Table 3. Post hoc tests for WAI and BMI

\begin{tabular}{|c|c|c|c|c|c|c|c|}
\hline & \multicolumn{3}{|c|}{ Estimates } & \multicolumn{4}{|c|}{ Pairwise comparisons } \\
\hline & \multirow[t]{2}{*}{ M } & \multirow[t]{2}{*}{ SD } & \multirow[t]{2}{*}{ M (differences) } & \multirow[t]{2}{*}{ SE } & \multirow[t]{2}{*}{ sign } & \multicolumn{2}{|c|}{$95 \% \mathrm{Cl}$} \\
\hline & & & & & & lower & upper \\
\hline \multicolumn{8}{|l|}{ WAI } \\
\hline 1 & 26.31 & 8.91 & $8.44(1-2)$ & 0.60 & $<0.001 * * *$ & 6.99 & 9.89 \\
\hline 2 & 34.74 & 7.49 & $0.96(2-3)$ & 0.54 & 0.210 & -0.32 & 2.27 \\
\hline 3 & 33.77 & 6.32 & $7.46(1-3)$ & 0.65 & $<0.001 * * *$ & 5.89 & 9.03 \\
\hline \multicolumn{8}{|l|}{ BMI } \\
\hline 1 & 45.67 & 7.34 & $11.76(1-2)$ & 0.39 & $<0.001 * * *$ & 10.83 & 12.69 \\
\hline 2 & 35.92 & 6.42 & $2.64(2-3)$ & 0.37 & $<0.001 * * *$ & 1.76 & 3.52 \\
\hline 3 & 33.28 & 5.25 & $14.40(1-3)$ & 054 & $<0.001 * * *$ & 13.26 & 15.54 \\
\hline
\end{tabular}

1-3, time points. ${ }^{* * *} p<0.001 . \mathrm{M}$, mean; SD, standard deviation; $\mathrm{SE}$, standard error; Sign, significance; $\mathrm{Cl}$, confidence interval; WAI, Work Ability Index; BMI, body mass index.

Fig. 2. WAI and BMI reduction after bariatric intervention. ; X-axis, WAI time points; Y-axis, WAI mean scores; dashed line, group with lower BMI reduction; solid line, group with higher BMI reduction. WAI, Work Ability Index; BMI, body mass index.

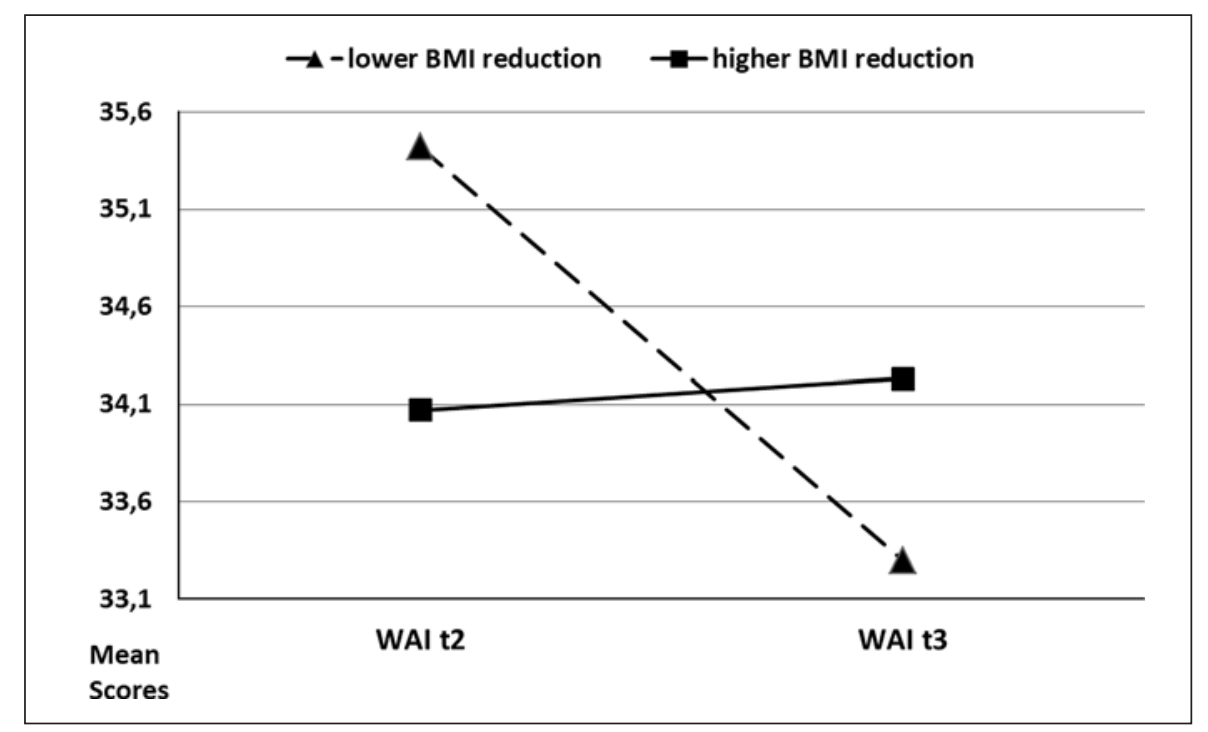

slight negative skewness was ascertained by the values of the WAI at the second measurement point. The range of the Cronbach's a values of the self-report measures varied between 0.76 and 0.84 at the first measurement point, between 0.69 and 0.77 at the second point, and between 0.69 and 0.63 at the last point. Mean value of the WAI scores at the first measurement point turned out to be in the lower fourth ( $\leq 25$ th percentile) of a reference population, indicating poor work ability [24]. At the second and last measurement points, the WAI scores range between the 25th and 50th percentile of a reference population, indicating moderate work ability. Excess weight loss at 6 and 12 months post-surgery was 49 and $66 \%$, respectively, while total body weight loss was documented at 23 and $31 \%$.
Repeated measures using ANOVA for the factor "WAI" revealed an effect, $F(1.9,373.69)=119.57, p<0.001$, $\eta^{2}=0.38$ (Fig. 1). Post hoc tests showed significant improvement between WAI $t 1$ and WAI $t 2$ and between WAI $t 1$ and WAI $t 3$, but not between WAI $t 2$ and WAI t3 (Table 3). For the factor "BMI," an ANOVA indicated an effect, $F(1.8,353.76)=699.04, p<0.001, \eta^{2}=0.78$ (Fig. 1), pointing to significant reduction of BMI after bariatric intervention. Post hoc tests showed significant decrease between BMI $\mathrm{t} 1$ and BMI $\mathrm{t} 2$, between BMI $\mathrm{t} 1$ and $\mathrm{BMI} \mathrm{t}$, and between BMI $\mathrm{t} 2$ and BMI $\mathrm{t} 3$ (Table 3 ).

A further analysis of covariance revealed no evidence that any significant influence of sociodemographic characteristics on WAI changed among the 3 measurement
40

Obes Facts 2022;15:36-45 DOI: $10.1159 / 000519269$
Köhler/Markov/Watschke/GrunerLabitzke/Böker/Kröger 
Table 4. Hierarchical multiple regression analysis of how demographic and psychosocial variables influence work ability 1 year after bariatric intervention

\begin{tabular}{|c|c|c|c|c|c|c|c|}
\hline \multirow{2}{*}{$\begin{array}{l}\text { Independent } \\
\text { variables }\end{array}$} & \multicolumn{7}{|c|}{ Dependent variable WAI 3} \\
\hline & B & $B(S E)$ & $\beta$ & $t$ & $p$ value & $R$ & $\begin{array}{l}\text { model } \\
\left(\Delta R^{2}\right)\end{array}$ \\
\hline WAI 1 & 0.24 & 0.05 & 0.34 & 4.97 & $<0.001 * * *$ & 0.32 & \\
\hline \multirow[t]{2}{*}{ KFzE 1} & 0.12 & 0.05 & 0.16 & 2.30 & $<0.001 * * *$ & 0.13 & \\
\hline & & & & & & & $0.12 *$ \\
\hline PHQ-9 1 & & & -0.12 & -1.47 & 0.14 & & \\
\hline BMI 1 & & & 0.05 & 0.79 & 0.43 & & \\
\hline $\mathrm{FLZ}^{\mathrm{M}} 1$ & & & 0.05 & 0.64 & 0.52 & & \\
\hline Sex 1 & & & -0.04 & -0.58 & 0.56 & & \\
\hline PFB-K 1 & & & -0.04 & -0.54 & 0.59 & & \\
\hline Age 1 & & & -0.01 & -0.04 & 0.96 & & \\
\hline
\end{tabular}

$B$, regression coefficient; $B(S E)$, standard error of regression coefficient; $\beta$, standardized prediction value; $t$, test value of prediction value; $p$, significance value; $R$, correlation prediction value; $t$, test value of prediction value; $p$, significance value; $R$, correlation
coefficient; $\Delta R^{2}$ (corrected $R^{2}$ ), value for the explained variance of All significant variables together in the hierarchical model; 1-3, time points. WAI, Work Ability Index; PHQ-9, Patient Health Questionnaire - Depression Scale; KFzE, Measure for Detecting Abnormal Eating Behavior; PFB-K, Short Relationship Satisfaction Questionnaire; FLZ ${ }^{\mathrm{M}}$, Life Satisfaction Questionnaire Modules. ${ }^{*} p<0.05$. ${ }^{* * *} p<0.001$.

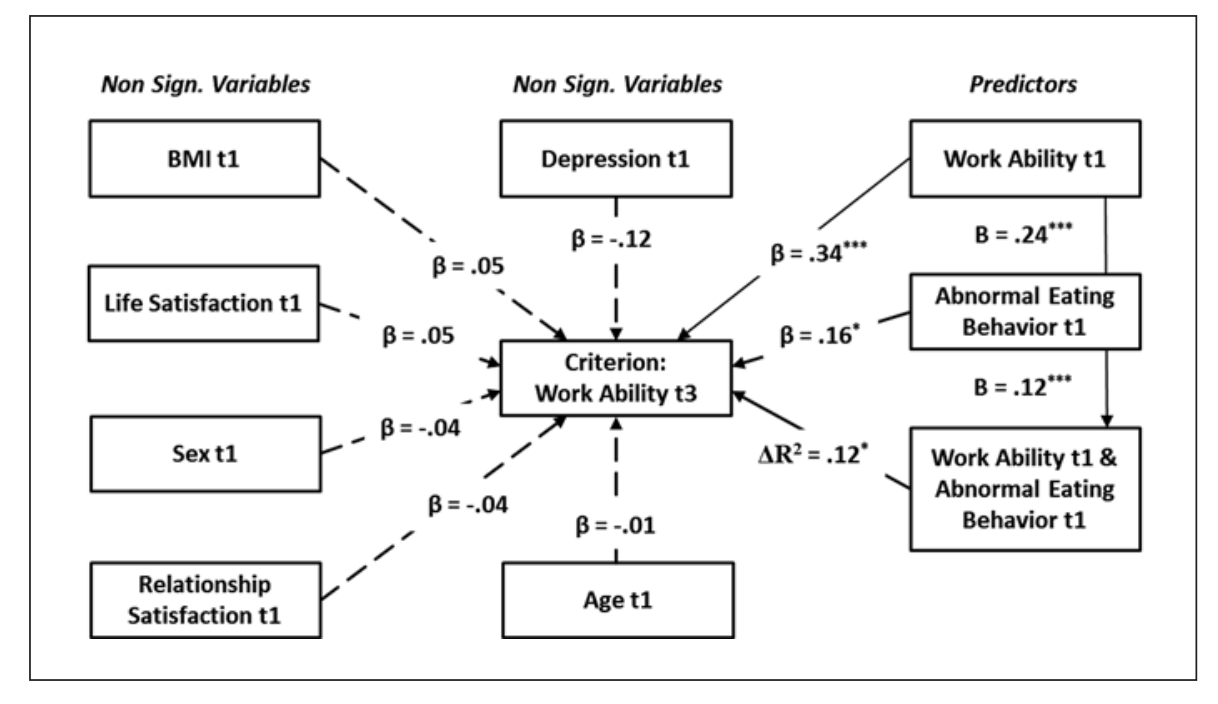

Fig. 3. Hierarchical multiple regression analysis of prediction of demographic and psychosocial variables during the preoperative visit ( $\mathrm{t} 1$ ) on work ability 1 year after bariatric intervention ( $\mathrm{t} 3)$. Boxes display independent variables, middle box includes criterion variable. Influences of nonsignificant variables on criterion variable are marked with dashed arrows, and influences of significant (predictor) variables are marked with solid arrows. $B$, regression coefficient; $\beta$, standardized prediction value; $\Delta R^{2}$ (Corrected $R^{2}$ ), value for the explained variance of all significant variables together in the hierarchical model; ${ }^{* * *} p<0.001,{ }^{*} p<0.05, \mathrm{t} 1-\mathrm{t} 3$, time points. BMI, body mass index. points. Only BMI changes from $\mathrm{t} 1$ to $\mathrm{t} 2$ and from $\mathrm{t} 2$ to $\mathrm{t} 3$ as covariates showed an impact on WAI changing, with the following effects: $F(1.9,364.99)=5.53, p=0.005, \eta^{2}=$ 0.03 (for $\mathrm{t} 1-\mathrm{t} 2$ difference) and $F(1.9,364.99)=4.59, p=$ $0.012, \eta^{2}=0.02$ (for $\mathrm{t} 2-\mathrm{t} 3$ difference). These effects point to a relation between stronger decrease of BMI and stronger increase of WAI over the course of time.

Considering the degree of $\mathrm{BMI}$ reduction at the last measurement time, an interaction effect between WAI t2 and $\mathrm{t} 3$ was observed, $F(1,195)=4.65, p=0.032, \eta^{2}=0.02$. Individuals in the higher BMI-reduction group remained almost constant from WAI t 2 to WAI $t 3$, while persons in the lower BMI reduction group decreased their WAI from t2 to $\mathrm{t} 3$ (Fig. 2).

The hierarchical multiple regression analysis revealed evidence for significant predictive values of WAI and KFzE at (t1) on WAI at (t3), with $R^{2}=0.12, F(2,194)=$ 14.07 , and $p<0.001$. The $R^{2}-$ value indicates the proportion of explained variance in WAI ( $\mathrm{t} 3$ ) by the best-fitted hierarchical model and shows whether newly added psychosocial and sociodemographic variables from (t1) entail a significant improvement of their predictions on WAI (t3). F-statistics and $p$ values show the amount of statistical strength and significance of the best-fitted hi- 
erarchical model. Conventionally, $R^{2}=0.12$ indicates a medium effect size of explained variance [25]. No other psychosocial and sociodemographic variable showed significant predictive value on WAI ( $\mathrm{t} 3$ ). Table 4 summarizes and Figure 3 visualizes these results.

Correlation tests showed moderate correlation coefficients of WAI $\mathrm{t} 3$ with WAI t1, FLZ ${ }^{\mathrm{M}}$, PHQ-9, and KFzE, followed by a small correlation coefficient with PFB-K and a very small correlation coefficient with age, BMI, and sex. Variance inflation factor was between 1.00 and 1.01 , which is far below the critical value of 10 and so met the condition of no evidence of high multicollinearity of variables among these variables [26]. Furthermore, there was no evidence for a suppressor effect of any variable in the hierarchical model.

\section{Discussion}

The results of the present study clearly indicate a significant increase in work ability at 6 months after bariatric surgery, with a persisting improved WAI level after 12 months. This replicates the findings of Askari et al. [10], who documented better ability to work and improved quality of life at follow-up of $>10$ years for gastric-bypass patients, based on the Bariatric Analysis and Reporting Outcome System (BAROS) survey [27].

Regarding the WAI, we found that $51.8 \%$ of the participants in this study reached a value that had to be classified as poor at the first measurement point. According to a German reference group [24], the mean value of WAI of all participants is in the category of the lowest $15 \%$ ( $\leq 25$ th percentile). At 6 and 12 months post-surgery, the WAI-scores range between the 25 th and 50th percentile of a reference population, indicating moderate work ability.

This significant increase in work ability after bariatric surgery still cannot reach average work-ability values. Interestingly, we found an inverse correlation between improvement of work ability and changes of body weight, meaning that greater decrease in BMI leads to an increase in work ability. Especially in the group with higher weight loss, the improvement of work ability remains at the improved level, whereas in the half with lower weight loss, the initial improvement at 6 months postsurgery reaches a higher value (Fig. 2), and then drops considerably within the next 6 months.

This finding indicates a so-called honeymoon effect for this group, with an abundance of positive changes after weight-loss surgery in the short run. The honeymoon period is a well-known phenomenon after bariatric surgery, in which persons' experience a limited time of improved mood and tranquility [28]. The passing of surgery anxiety and improvement in self-image can lead to higher scores on psychosocial surveys [29]. Booth et al. [30] described this effect for depressive symptoms, in which symptoms were reduced during the initial postoperative period and did not require maintenance in the long run. As shown in Table 1, this effect was confirmed by our study regarding the levels of depression (PHQ-9) and life satisfaction $\left(\mathrm{FLZ}^{\mathrm{M}}\right)$. Interestingly, the level of relationship satisfaction (PFB-K) did not show a honeymoon effect and remained on a high level 12 months after surgery. Furthermore, positive development of one's work ability might be depressed by an overall disappointment in weight loss performance for individuals with lower BMI loss [7].

With respect to the influence of psychosocial factors on changes in work ability, we found a predictive value only for dysfunctional eating behavior (KFzE), with an inverse correlation between the 2 . This finding means that the more the individuals suffer from dysfunctional eating behavior at preoperative examination, the more improvement of work ability is reported in the postoperative year. Suffering from dysfunctional eating behavior might be associated with other psychosocial characteristics (e.g., perfectionism and performance orientation) that also promote work ability. Interestingly, in our earlier report [16], eating behavior prior to surgery had no predictive value on work ability as it had on age, depressive states, and life satisfaction. The amount of depression is enhanced in the obese population $[1,31]$ and impairs work ability $[9,32]$. Against our hypothesis and in contrast to the findings of Sockalingam et al. [14], we could not show a correlation between self-reported depressive complaints and changes in work ability in the postoperative course. In a 12-months follow-up assessment, Sockalingam et al. [14] described how a history of mental disorders was not a predictor for work-related impairment after bariatric surgery, but improvements in depression, anxiety, and mental quality of life went along with the greatest changes in work-ability improvement. Also, work-related impairment prior to surgery led to higher scores 12 months after bariatric surgery, as employment-related functioning normalized. In the present study, work ability showed a significant improvement postoperatively over 12 months but could reach only moderate values. In contrast to the data of Sockalingam et al. [14], however, concurrent to our hypothesis, we revealed a correlation between improvement of work ability and the extent of weight loss.
Köhler/Markov/Watschke/GrunerLabitzke/Böker/Kröger 
Furthermore, we did not find a predictive value for age in the present study. A systemic literature review [33] revealed inconsistent data as well. Four out of 7 studies reported a decreased WAI with greater age, while 2 studies found no association, and 1 study reported a higher risk of poor WAI among younger workers. Our findings might be the result of a constant striving by companies and state-funded entities (e.g., pension insurance) in Germany to encourage patients in return-to-work and maintain work measures.

Overall, only a limited body of knowledge in the literature discusses the influence of sociodemographic variables and psychosocial factors and their predictive value with respect to work ability following weight-loss surgery. Improvement of work ability after bariatric surgery may lead to support for the economy in the form of increased employment rates. In a recent review of psychosocial changes after bariatric surgery, Doni et al. [8] suggested long-term support by specially trained health professionals, to maintain patients' improvements.

The results suggest the positive impact of weight-loss surgery on work ability, and indicate a proportionate predictive value for the extent of weight loss and dysfunctional eating behavior. Against our hypothesis, and in contrast to earlier research [14], predictive value for depressive symptoms and age was not revealed.

Several limitations had to be taken into consideration. First, patients from only a single health center in 1 country were investigated, such that the results may not be comparable to those found for other countries or cultures. Second, participation in the study was completely voluntary, and the results do not reflect what may be true for the obese population in Germany as a whole. Third, as a health-insurance eligibility requirement for reimbursement, all participants attended a 6-month training program prior to bariatric surgery. This was revealed as a limitation in the course of earlier research, which showed that surgery candidates often underreport symptoms related to self-report inventories as part of diagnostic interviews [34]. Fourth, the fact that $>80 \%$ of our patients were female might also add bias to the study, but this distribution of gender is typical for bariatric surgery patients. Of the bariatric patients featured in recently published data from North America, 79\% were female [35], while in Germany, data for obese patients who underwent bariatric procedures and were prospectively registered in an online database revealed a distribution of $64 \%$ female patients [36].

Another limitation of this study was the sole application of a self-report measure for conducting work ability.
The number of days of incapacity to work postsurgery gathered by health insurers might differ from what participants reported themselves; their answers might be biased in their own favor, and also allow more detailed analyses of the postoperative course and the point in time at which return-to-work was possible. Finally, only persons seeking bariatric surgery by itself, independent of other weight-loss methods, were considered, and no normalweight group served as a control.

This study has the following strengths. Our unique longitudinal design included a homogenous study-group of patients anticipating bariatric surgery, plus postoperative follow-up at 6 and 12 months. Unfortunately, we were not able to provide compensation or payment for participation, such that not all the participants were willing to fill in the study forms during routine follow-up visits. On the other hand, to counteract this limitation, we used the well-established calculation method of multiple imputations for substitution of missing data [23] to meet the statistical assumptions for reliable calculations. Also, for greater consistency and reliability, we used the recommended standardized measures that have previously been utilized in bariatric surgery research.

\section{Conclusion}

While bariatric surgery-induced weight loss is associated with an increase in work ability that correlates with the amount of weight lost, this increase could not reach the average work-ability values of a reference population. A trend of influence was seen for sustained improvement of work ability in the group with greater weight loss.

An influence of psychosocial factors on improvement in work ability was seen for dysfunctional eating behavior, but not for the patient's age, depressive symptoms, or life satisfaction. Further studies should extend the investigation beyond 1 year and determine how interventions can support and maintain improvements in work ability following bariatric surgery, in order to reduce sick leave and unemployment in the affected population.

\section{Statement of Ethics}

All procedures were in accordance with good clinical practice, and fell within the parameters set by the Declaration of Helsinki. Written informed consent was obtained from all patients. The study was approved by the Institutional Ethics Committee of the University of Braunschweig (M-2015-07). 


\section{Conflict of Interest Statement}

The authors declare that they have no conflict of interest.

\section{Funding Sources}

This study did not receive any funding.

\section{Author Contributions}

Hinrich Köhler contributed to the concept of study design, data acquisition, and drafting of manuscript. Valentin Markov contributed to statistical analysis and drafting of manuscript. Kerstin
Gruner-Labitzke and Anna Watschke contributed to data acquisition and critical revision of manuscript. Clara Böker contributed to critical revision of manuscript. Christoph Kröger contributed to the concept of study design, statistical analysis, critical revision of manuscript, and data postprocessing. We confirm that the final version of this paper was read and approved by all of the authors.

\section{Data Availability Statement}

The raw data supporting the conclusions of this article will be made available by the authors.

\section{References}

1 Dawes AJ, Maggard-Gibbons M, Maher AR, Booth MJ, Miake-Lye I, Beroes JM, et al. Mental health conditions among patients seeking and undergoing bariatric surgery: a meta-analysis. JAMA. 2016; 315(2):150-63.

2 Gryth K, Persson C, Näslund I, Sundbom M, Näslund E, Stenberg E. The influence of socioeconomic factors on quality-of-life after laparoscopic gastric bypass surgery. Obes Surg. 2019;29(11):3569-76.

3 Wimmelmann CL, Dela F, Mortensen EL. Psychological predictors of mental health and health-related quality of life after bariatric surgery: a review of the recent research. Obes Res Clin Pract. 2014;8(4):e314-24.

4 Baumeister H, Härter M. Mental disorders in patients with obesity in comparison with healthy probands. Int J Obes. 2007;31(7): 1155-64.

5 Greenberg I, Perna F, Kaplan M, Sullivan MA. Behavioral and psychological factors in the assessment and treatment of obesity surgery patients. Obes Res. 2005;13(2):244-9.

6 Herpertz S, Kielmann R, Wolf AM, Langkafel $M$, Senf W, Hebebrand J. Does obesity surgery improve psychosocial functioning? A systematic review. Int J Obes Relat Metab Disord. 2003;27(11):1300-14

7 Karlsson J, Taft C, Rydén A, Sjöström L, Sullivan M. Ten-year trends in health-related quality of life after surgical and conventional treatment for severe obesity: the SOS intervention study. Int J Obes. 2007;31(8):124861.

8 Doni K, Breuing J, Pieper D. Psychosocial changes of bariatric surgery in patients' everyday life: a scoping review. Obes Surg. 2020; 30(8):2949-56.
9 Andersen LL, Izquierdo M, Sundstrup E. Overweight and obesity are progressively associated with lower work ability in the general working population: cross-sectional study among 10,000 adults. Int Arch Occup Environ Health. 2017;90(8):779-87.

10 Askari A, Dai D, Taylor C, Chapple C, Halai $\mathrm{S}$, Patel $\mathrm{K}$, et al. Long-term outcomes and quality of life at more than 10 years after laparoscopic roux-en-y gastric bypass using bariatric analysis and reporting outcome system (BAROS). Obes Surg. 2020;30(10):3968-73.

11 van Duijvenbode DC, Hoozemans MJ, van Poppel MN, Proper KI. The relationship between overweight and obesity, and sick leave: a systematic review. Int J Obes. 2009;33(8): 807-16.

12 Ewing BT, Thompson MA, Wachtel MS, Frezza EE. A cost-benefit analysis of bariatric surgery on the south plains region of Texas. Obes Surg. 2011;21(5):644-9.

13 Arterburn D, Westbrook EO, Ludman EJ, Operskalski B, Linde JA, Rohde P, et al. Relationship between obesity, depression, and disability in middle-aged women. Obes Res Clin Pract. 2012;6(3):e197-206.

14 Sockalingam S, Wnuk S, Kantarovich K, Meaney C, Okrainec A, Hawa R, et al. Employment outcomes one year after bariatric surgery: the role of patient and psychosocial factors. Obes Surg. 2015;25(3):514-22.

15 Masheb RM, White MA, Toth CM, BurkeMartindale CH, Rothschild B, Grilo CM. The prognostic significance of depressive symptoms for predicting quality of life 12 months after gastric bypass. Compr Psychiatry. 2007; 48(3):231-6.

16 Kohler H, Markov V, Watschke A, GrunerLabitzke K, Boker C, Mall J, et al. Psychosocial predictors of work ability in morbidly obese patients: results of a Cross-Sectional Study in the context of bariatric surgery. Obesity Facts. 2021;14(1):56-63.
17 Kroenke K, Spitzer RL, Williams JB. The PHQ-9: validity of a brief depression severity measure. J Gen Intern Med. 2001;16(9):60613.

18 Kliem S, Job AK, Kröger C, Bodenmann G, Stöbel-Richter Y, Hahlweg K, et al. Entwicklung und normierung einer Kurzform des partnerschaftsfragebogens (PFB-K) an einer repräsentativen deutschen Stichprobe. Z Klin Psychol Psychother (Gott). 2012;41(2):81-9.

19 Tuomi K, Ilmarinen J, Jahkola A, Katajarinne L, Tulkki A. Work ability index. 2nd ed. Helsinki: Finnish Institute of Occupational Health; 1998.

20 Henrich G, Herschbach P. Questions on life satisfaction (FLZ M): a short questionnaire for assessing subjective quality of life. Eur J Psychol Assess. 2000;16(3):150-9.

21 Wernze H, Rühl H. (Short questionnaire for detecting abnormal eating behavior (binge eating). Test results in 320 persons with normal weight and overweight/obesity). Dtsch Med Wochenschr. 2007;132(31-32):1613-8.

22 Little RJA. A test of missing completely at random for multivariate data with missing values. J Am stat Assoc. 1988;83(404):1198-202.

23 Rubin DB. Multiple Imputation for nonresponse in surveys. New York: Wiley \& Sons; 1987.

24 Hasselhorn HM, Freude G. Der work-abilityIndex: ein leitfaden. Dortmund: Wirtschaftsverlag NW, Verlag für Neue Wissenschaft; 2007.

25 Cohen J. A power primer. Psychol Bull. 1992; 112(1):155-9.

26 Tabachnick BG, Fidell LS. Using Multivariate Statistics. 5th ed. New York: Allyn and Bacon; 2007.

27 Wolf AM, Falcone AR, Kortner B, Kuhlmann HW. BAROS: an effective system to evaluate the results of patients after bariatric surgery. Obes Surg. 2000;10(5):445-50. 
28 Mazer LM, Azagury DE, Morton JM. Quality of life after bariatric surgery. Curr Obes Rep. 2017;6(2):204-10.

29 Biron S, Biertho L, Marceau S, Lacasse Y. Long-term follow-up of disease-specific quality of life after bariatric surgery. Surg Obes Relat Dis. 2018;14(5):658-64.

30 Booth H, Khan O, Prevost AT, Reddy M, Charlton J, Gulliford MC, et al. Impact of bariatric surgery on clinical depression. Interrupted time series study with matched controls. J Affect Disord. 2015;174:644-9.

31 Kessler RC, Adler L, Ames M, Demler O, Faraone S, Hiripi E, et al. The World Health Organization adult $\mathrm{ADHD}$ self-report scale (ASRS): a short screening scale for use in the general population. Psychol Med. 2005;35(2):245-56.

32 Tonnon SC, Robroek SRJ, van der Beek AJ, Burdorf A, van der Ploeg HP, Caspers M, et al. Physical workload and obesity have a synergistic effect on work ability among construction workers. Int Arch Occup Environ Health. 2019;92(6):855-64.

33 van den Berg TI, Elders LA, de Zwart BC, Burdorf A. The effects of work-related and individual factors on the work ability index: a systematic review. Occup Environ Med. 2009; 66(4):211-20.

34 Cassin S, Sockalingam S, Hawa R, Wnuk S, Royal S, Taube-Schiff M, et al. Psychometric properties of the patient health questionnaire (PHQ-9) as a depression screening tool for bariatric surgery candidates. Psychosomatics. 2013;54(4):352-8.

35 Dang JT, Shelton J, Mocanu V, Sun W, Birch DW, Karmali S, et al. Trends and outcomes of laparoscopic sleeve gastrectomy between 2015 and 2018 in the USA and Canada. Obes Surg. 2021 Feb;31(2):675-81.

36 Benedix F, Benedix DD, Knoll C, Weiner R, Bruns $C$, Manger T, et al. Are there risk factors that increase the rate of staple line leakage in patients undergoing primary sleeve gastrectomy for morbid obesity? Obes Surg. 2014 Oct:24(10):1610-6. 